SMALL INTESTINE

\title{
Early interactions of Salmonella enterica serovar typhimurium with human small intestinal epithelial explants
}

\author{
A Haque, F Bowe, R J Fitzhenry, G Frankel, M Thomson, R Heuschkel, S Murch, M P Stevens, \\ T S Wallis, A D Phillips, G Dougan
}

Gut 2004;53:1424-1430. doi: 10.1136/gut.2003.037382

See end of article for authors' affiliations

....................

Correspondence to:

Dr A Haque, Immunology

Unit, Department of

Infectious and Tropical

Diseases, London School of

Hygiene and Tropical

Medicine, Keppel St,

London WCIE 7HT, UK;

ashraful.haque@

Ishtm.ac.uk

Revised version received 13 February 2004

Accepted for publication

17 March 2004
Background: Salmonella enterica serovar typhimurium (S typhimurium) causes invasive gastroenteritis in humans, a disease involving significant penetration of the intestinal mucosa. However, few studies have been undertaken to investigate this interaction directly using differentiated human gut tissue.

Aims: To investigate the early interactions of an enteropathogenic strain of $S$ typhimurium with human intestinal mucosa using human intestinal in vitro organ culture (IVOC).

Methods: Wild-type and mutant derivatives of S typhimurium TML were used to compare interactions with cultured human epithelial cells, bovine ligated loops, and human intestinal IVOC.

Results: $S$ typhimurium TML was shown to attach to cultured Caco-2 brush border expressing cells and cause tissue damage and fluid accumulation in a ligated bovine loop model. $S$ typhimurium TML bound predominantly to the mucus layer of human IVOC explants during the first four hours of IVOC incubation. From four to eight hours of IVOC incubation, small but characteristic foci of attaching and invading $S$ typhimurium TML were detected as clusters of bacteria interacting with enterocytes, although there was no evidence for large scale invasion of explant tissues. Ruffling of enterocyte membranes associated with adherent Salmonella was visualised using electron microscopy.

Conclusions: Human IVOC can be used as an alternative model for monitoring the interactions between $S$ typhimurium and human intestinal epithelium, thus potentially offering insight into the early stages of human Salmonella induced gastroenteritis.
S almonella enterica serovars, such as $S$ enterica serovar typhimurium (S typhimurium), are leading causes of self limiting non-typhoidal gastroenteritis in humans. ${ }^{12}$ Studies using the mouse, together with in vitro models such as cultured eukaryotic cells, have yielded details about the molecular and genetic events that underpin some aspects of Salmonella virulence. ${ }^{34}$ However, it has been relatively difficult to directly assess the contribution made by Salmonella associated virulence genes to human gastroenteritis as in vitro cultured human epithelial cells and the adult mouse cannot mimic many aspects of the pathogenesis of this human disease syndrome. ${ }^{5}$ Studies in some farm animal hosts, such as cattle that develop a pyrexial mucopurulent diarrhoeal disease similar to that in humans, have improved our understanding of the cellular and molecular events that occur during $S$ enterica associated gastroenteritis. ${ }^{6}$ However, we felt it would be instructive to examine the interactions between $S$ typhimurium and fully differentiated human gut epithelial tissue. This is important because, remarkably, to our knowledge there are no recent studies employing this direct approach. Consequently, we utilised an in vitro organ culture (IVOC) system that has been used previously to study bacterial interactions with human intestinal epithelium ${ }^{7-10}$ to assess $S$ typhimurium interactions with human terminal ileal epithelial tissue.

\section{MATERIALS AND METHODS Bacterial strains and media}

$S$ typhimurium TML, obtained from Microscience Ltd (Berkshire, UK), was originally isolated from a clinical case of gastroenteritis. ${ }^{11} S$ typhimurium 4/74 (ST4/74) is a bovine isolate. ${ }^{12}$ For all infection assays, except the bovine ligated loop assay, $S$ typhimurium TML was cultured statically, overnight, at $37^{\circ} \mathrm{C}$ in Luria-Bertani broth (LB broth). ${ }^{13}$ For the bovine ligated loop assay, bacteria were initially cultured as above, but were then subcultured in LB broth at a ratio 1:3 for three hours at $37^{\circ} \mathrm{C}$ with shaking $(220 \mathrm{rpm})$. Bacteria prepared using LB broth culture were not washed prior to inoculation of bovine ligated loops.

\section{Human intestinal in vitro organ culture assay}

Tissue was obtained with fully informed parental consent and local ethics committee approval using grasp forceps during routine endoscopic (Olympus PCF paediatric endoscope) investigation of intestinal disorders. Terminal ileal biopsies were taken from areas showing no macroscopic abnormalities. Light microscopy subsequently showed no histological abnormality. IVOC infections were performed as described previously. ${ }^{7}$ Briefly, $25 \mu \mathrm{l}$ of an overnight bacterial culture were inoculated directly onto biopsy samples, which had been immobilised, mucosal side facing up, in petri dishes on foam supports soaked in IVOC medium (Dulbecco's minimal essential medium and NCTC-135 medium in a $1: 1$ volume ratio, and 10\% newborn calf serum; Sigma-Aldrich Co. Ltd, Poole, UK). Samples were gassed with $95 \% \mathrm{O}_{2}-5 \%$ $\mathrm{CO}_{2}$ in an airtight container and maintained on a rocking platform at $37^{\circ} \mathrm{C}$. The IVOC medium was changed every two hours and assays were terminated at 2, 4, 6, or 8 hours.

In some cases, gentamicin protection assays were performed on tissue that had been incubated with bacteria for four hours. These tissue samples were incubated for a further hour in tissue culture medium containing gentamicin $(100 \mu \mathrm{g} / \mathrm{ml})$. Biopsies were washed to remove mucus and

Abbreviations: $\mathrm{C} 2 \mathrm{BBe}$, Caco-2 brush border expressing; ELISA, enzyme linked immunosorbent assay; IVOC, in vitro organ culture; $L B$, Luria Bertani; $\mathrm{OsO}_{4}$, osmium tetroxide; PBS, phosphate buffered saline; SEM, scanning electron microscopy; TEM, transmission electron microscopy 


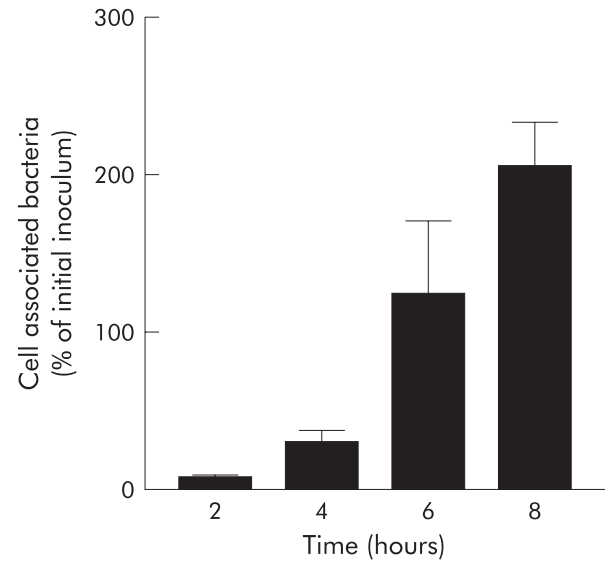

Figure 1 Salmonella enterica serovar typhimurium (S typhimurium) TML invades Caco-2 brush border expressing (C2BBe) cells. C2BBe cells, infected with $S$ typhimurium TML at a ratio of 10 bacteria per epithelial cell, were washed, lysed, and the released bacteria counted at 2, 4, 6 , and 8 hours post infection. This experiment was performed in triplicate wells and was repeated once.

antibiotic, homogenised, and the homogenate plated out on $\mathrm{L}$ agar to enumerate bacteria. Other tissue samples were treated in a number of different ways at the end of the incubation period. Samples to be analysed by scanning electron microscopy (SEM) were fixed in $2.5 \%$ phosphate buffered glutaraldehyde and post fixed in $1 \%$ aqueous osmium tetroxide $\left(\mathrm{OsO}_{4}\right)$. Samples to be analysed by transmission electron microscopy (TEM) were fixed in $2.5 \%$ glutaraldehyde $/ 2 \%$ paraformaldehyde in $0.1 \mathrm{M}$ sodium cacodylate, and post fixed in $1 \%$ aqueous $\mathrm{OsO}_{4}$. Samples to be analysed by light microscopy were fixed in 3.7\% formaldehyde in phosphate buffered saline (PBS), dehydrated, paraffin embedded, and sectioned at $4 \mu \mathrm{m}$ thickness, before being stained with haematoxylin and eosin. Areas of bacterial/epithelial cell interaction ("foci of infection") were detected by microscopic analysis of this tissue. A minimum of 50 villus sections from five non-consecutive tissue sections were counted per sample.

\section{Bovine ligated ileal loop assay}

Twenty eight day old Friesan bull calves were anaesthetised with pentobarbital $(0.44 \mathrm{mg} / \mathrm{kg}$ body weight $)$ for the duration of the experiment. The abdominal wall was opened by a midline incision, the distal ileum was exteriorised, and the intestinal lumen was flushed with PBS. Loops, $5 \mathrm{~cm}$ in length, with $1 \mathrm{~cm}$ spaces in between them, were constructed using surgical silk. Prepared inocula $(5 \mathrm{ml})$ in LB broth were injected into each loop, and control loops injected with sterile LB broth. The loops were returned to the abdominal cavity and the wound was repaired. Twelve hours after inoculation, the ileum was exteriorised, the loops cut out, and the tissue fixed in $2.5 \%$ phosphate buffered glutaraldehyde, and postfixed in $1 \%$ aqueous $\mathrm{OsO}_{4}$ for subsequent analysis by SEM.

\section{Caco-2 brush border expressing epithelial cell invasion assay}

Caco-2 brush border expressing (C2BBe) cells were maintained in Dulbecco's modified Eagle's medium with $4 \mathrm{mM}$ L-glutamine, adjusted to contain $1.5 \mathrm{~g} / \mathrm{l}$ sodium bicarbonate, $4.5 \mathrm{~g} / \mathrm{l}$ glucose $(90 \%)$, and fetal calf serum (10\%) supplemented with $0.01 \mathrm{mg} / \mathrm{ml}$ human transferrin. Cells were grown to confluency and differentiated for 14 days before use in invasion assays. Monolayers were infected in triplicate wells at a multiplicity of infection of 10 with bacteria that had been harvested from LB broth cultures by centrifugation,
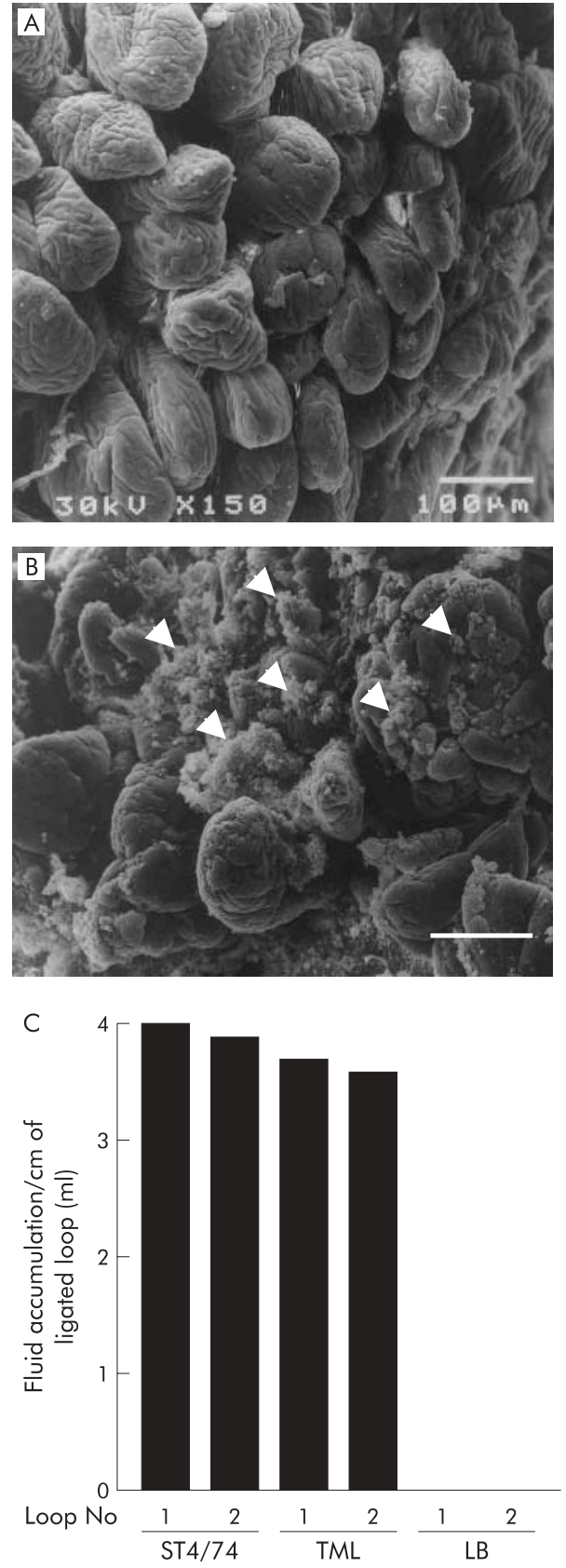

Figure 2 Salmonella enterica serovar typhimurium (S typhimurium) TML induces damage to villi and secretory responses in bovine ligated ileal loops. (A) Representative scanning electron microscopy (SEM) image showing intact villi lining the mucosal surface of bovine ligated loops injected with Luria Bertani (LB) broth and incubated for 12 hours. (B) Representative SEM image showing extensive epithelial damage with extrusion of enterocytes (arrowheads) from the mucosal surface of bovine loops injected with LB broth containing $S$ typhimurium TML and incubated for 12 hours (bar $=100 \mu \mathrm{m})$. (C) The secretory response was measured 12 hours after injection of bovine ligated loops with LB broth, the positive control strain (ST4/74), or S typhimurium TML. The secretory response is expressed here as the volume of liquid accumulated within a loop/length of the loop.

washed once in PBS, and diluted to the desired concentration in tissue culture medium. Infected monolayers were centrifuged at $250 \mathrm{~g}$ for five minutes and then incubated for 20 minutes at $37^{\circ} \mathrm{C} / 5 \% \mathrm{CO}_{2}$. After such time, monolayers were extensively washed and incubated at $37^{\circ} \mathrm{C} / 5 \% \mathrm{CO}_{2}$. At various time points, culture supernatants were collected, and monolayers were washed, lysed with detergent $(0.1 \%$ Triton 

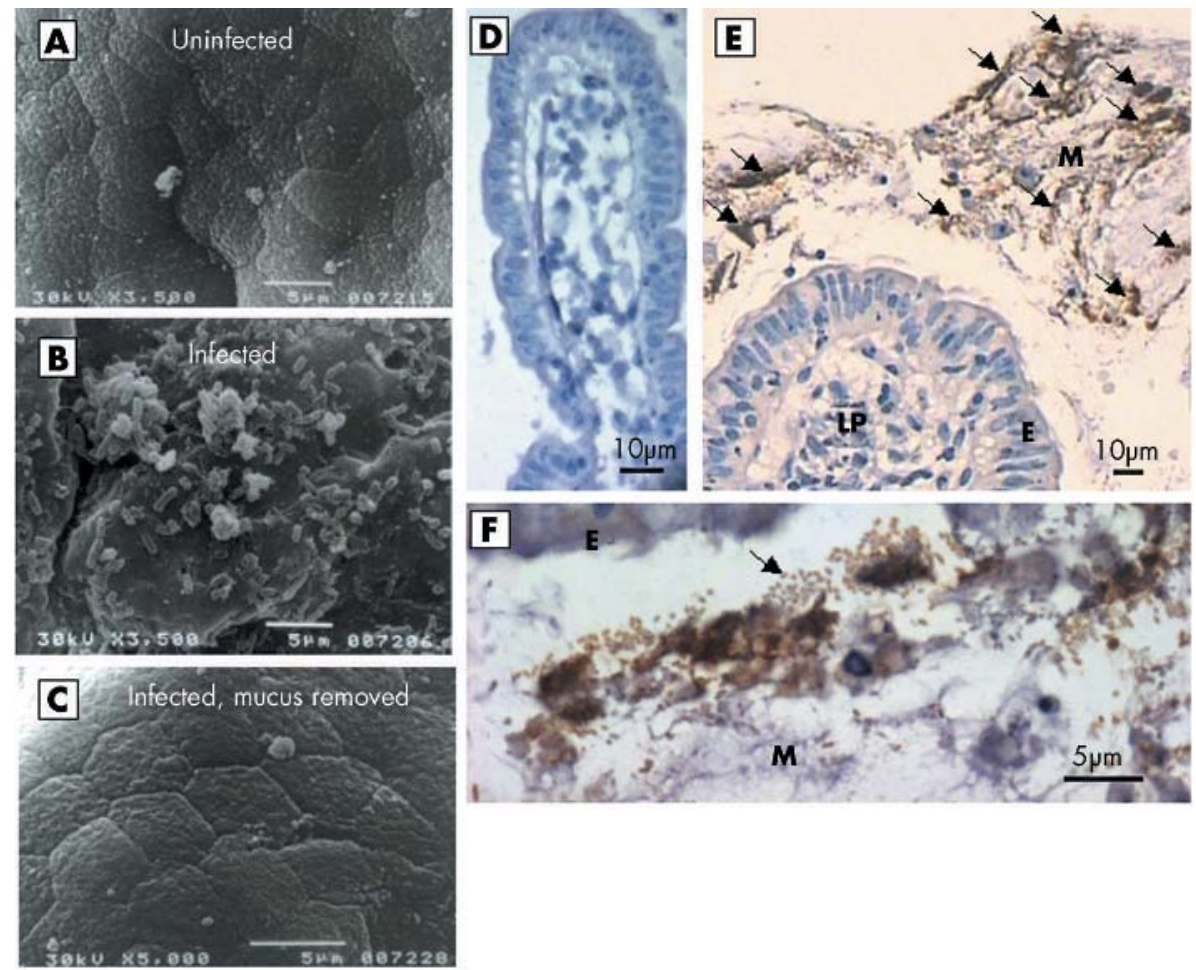

Figure 3 Salmonella enterica serovar typhimurium (S typhimurium) TML adheres to mucus overlying human terminal ileal epithelial tissue. (A) Scanning electron microscopy (SEM) analysis of uninfected human terminal ileal epithelial tissue, incubated by in vitro organ culture (IVOC) for four hours, revealed a mosaic appearance of the apical surface of gut enterocytes unobstructed by mucus. (B) SEM analysis of human terminal ileal epithelial tissue, incubated by IVOC for two and four hours with S typhimurium TML, revealed large numbers of uniform rod-shaped bacilli, $\sim 1.5 \mu \mathrm{m}$ in length, located in a mucus layer covering the tissue. (C) SEM analysis of human terminal ileal epithelial tissue, incubated by IVOC for two and four hours with $S$ typhimurium TML and then washed to remove mucus, revealed no obvious damage or bacteria on apical epithelial cell surfaces. (D-F) Immunostaining of $4 \mu \mathrm{m}$ thick paraffin sections from four hour IVOC samples, uninfected (D) or inoculated with $S$ typhimurium TML (E, F). Staining was performed using inhouse polyclonal sera from rabbits immunised with $S$ typhimurium. Extensive brown peroxidase staining (arrows) was observed in mucus (M), overlying villi but not in epithelial cells (E), or lamina propria (LP) of the villi themselves. (F) Higher magnification (100×) revealed individual bacilli in mucus $(M)$, overlying epithelial cells $(E)$, and staining for brown peroxidase stain.

$\times 100)$, and the lysate diluted and plated out to determine bacterial viable counts.

\section{RESULTS}

Phenotypic characterisation of $S$ typhimurium TML interactions with cultured human Caco- 2 cells and in bovine ligated loop assays

To our knowledge, no other studies have yet been published describing the interaction of $S$ typhimurium with explanted human intestinal tissues. Consequently, it was important to carefully characterise and validate the pathogenicity and invasiveness of the $S$ typhimurium strain selected for the study. S typhimurium TML was originally isolated from a case of human gastroenteritis and has been shown to be enteropathogenic when tested in rabbit ligated ileal loops. ${ }^{14}$ More recently, mutant derivatives of the same isolate utilised in this study were shown to colonise the human intestine of volunteers. ${ }^{15}$ Initially, the ability of $S$ typhimurum TML to interact in vitro with the immortalised epithelial cell line, C2BBe, was investigated. C2BBe cells form a polarised monolayer with an apical brush border morphologically comparable with that of the human colon. ${ }^{16} S$ typhimurium TML associated readily with C2BBe cells $(\sim 7 \%$ of the original inoculum after two hours of incubation) and was not dislodged by extensive washing of monolayers prior to detergent lysis (fig 1). This suggests that bacteria were binding strongly to the epithelial cell surface and/or were invading the cells.

The enteropathogenicity of $S$ typhimurium TML in vivo was then investigated using a bovine ligated ileal loop assay as this is one of the best models for studying Salmonella induced enteritis in non-human species. SEM analysis of control loops, which had been injected with LB broth into the lumen, demonstrated good preservation of gut mucosal architecture, with no evidence of damage to villi lining the gut (fig 2A). In contrast, SEM analysis of loops injected with either $S$ typhimurium TML into the lumen or a well characterised bovine virulent strain, $S$ typhimurium $4 / 74$, showed extensive damage to villi lining the gut (fig 2B). Accumulation of fluid, secreted into ligated ileal loops, is a reliable indicator of the enteropathogenicity of Salmonella serovars. ${ }^{17}{ }^{18}$ There was no significant fluid accumulation in loops injected with LB broth (fig 2C). In contrast, both the positive control strain $S$ typhimurium 4/74 and $S$ typhimurium TML induced fluid secretion responses (fig $2 \mathrm{C}$ ).

\section{Interaction of Styphimurium TML with human terminal ileal epithelial tissue maintained by IVOC}

Terminal ileal biopsies, maintained by IVOC, were initially incubated for two hours and four hours with $S$ typhimurium TML, and for eight hours with enteropathogenic Escherichia coli strain E2348/69. E2348/69 has been shown previously to produce attaching and effacing lesions on the surface of human intestinal tissue biopsies under these conditions ${ }^{7}$ and such lesions were again observed during the course of this work (data not shown).

Assays with $S$ typhimurium TML were performed on six different days, with tissue from a different patient each day. In $3 / 3$ cases for four hour incubations and $3 / 3$ cases for four hour incubations, uniform rod-shaped bacilli were seen by 
Table 1 Gentamicin resistant Salmonella enterica serovar typhimurium (S typhimurium) TML following incubation with in vitro organ culture

\begin{tabular}{llll}
\hline Patient & $\begin{array}{l}\text { No of gentamicin protected } \\
\text { S typhimurium in uninfected } \\
\text { control tissue } \\
\text { (cfu/mg of tissue) }\end{array}$ & $\begin{array}{l}\text { No of gentamicin protected } \\
\text { S typhimurium in } \\
\text { infected tissue } \\
\text { (cfu/mg of tissue) }\end{array}$ & $\begin{array}{l}\text { \% Gentamicin protected } \\
\text { S typhimurium } \\
\text { (original inoculum } \\
1.25 \times 10^{6} \text { cfu/mg) }\end{array}$ \\
\hline 1 & 0 & 538 & 0.04 \\
1 & & 667 & 0.05 \\
2 & 0 & 481 & 0.04 \\
2 & & 515 & 0.04 \\
3 & 0 & 1451 & 0.12 \\
3 & 0 & 4083 & 0.33 \\
4 & 0 & 6407 & 0.19 \\
4 & & 681 & 0.05 \\
\hline
\end{tabular}

SEM to be associated with a mucus layer overlying the tissue (fig 3B). Interestingly, no mucus layer was discernible by SEM above uninfected IVOC samples maintained for two or four hours, suggesting that infected samples differed from uninfected samples in the quantity of mucus they secreted (fig 3A). This suggests that mucus accumulation could be stimulated by the presence of the Salmonella bacteria on the IVOC sample. Importantly, no bacilli-shaped structures were seen on uninfected control tissues, suggesting that commensal gut flora from the patient did not present a contamination problem in these studies (fig 3A). SEM analysis of the biopsies from six patients incubated for either two or four hours, and whose mucus had been washed off prior to glutaraldehyde fixation, revealed no obvious cases $(0 / 6)$ of epithelial cell damage or clear evidence of Salmonella induced membrane ruffling at these early time points compared with uninoculated control tissue (fig 3C). Immunohistochemical analysis of paraffin embedded tissue sections using polyclonal rabbit antisera directed against $S$ typhimurium demonstrated strong positive staining of bacilli in the mucus above infected samples (fig 3E, F) but with little obvious staining associated with villi of either uninfected control samples (fig 3D) or villi of infected samples (fig 3E). This suggested that after two and four hour incubations, the vast majority of $S$ typhimurium TML were located in a freshly secreted mucus layer above tissue explants.
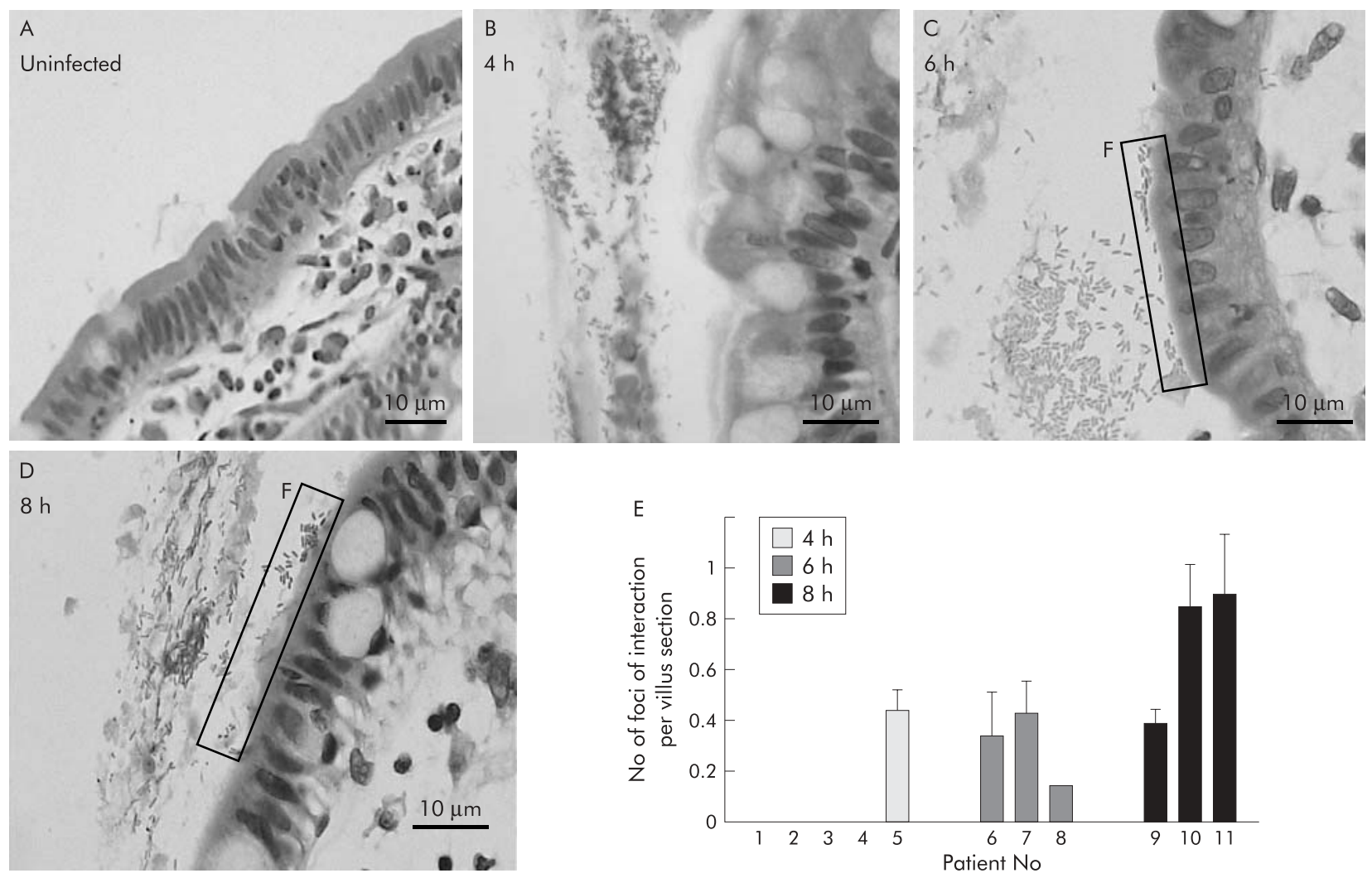

Figure 4 Salmonella enterica serovar typhimurium (S typhimurium) TML interacts at discrete foci with the brush border of human terminal ileal epithelium. Human terminal ileal epithelial tissue samples from 11 patients were incubated by in vitro organ culture (IVOC), either as uninfected controls (A) or with S typhimurium TML for four hours (five cases) (B), six hours (three cases) (C), or eight hours (three cases) (D). (B) Tissue sections were stained with haematoxylin-eosin and then analysed by light microscopy to search for areas along the apical surface of the epithelial cell monolayer where bacteria appeared closely associated with the tissue. Such areas were termed "foci of interaction" (F) (C, D). (E) Data depict the mean (SD) number of "foci of interaction" observed on $4 \mu \mathrm{m}$ thick villus sections. 


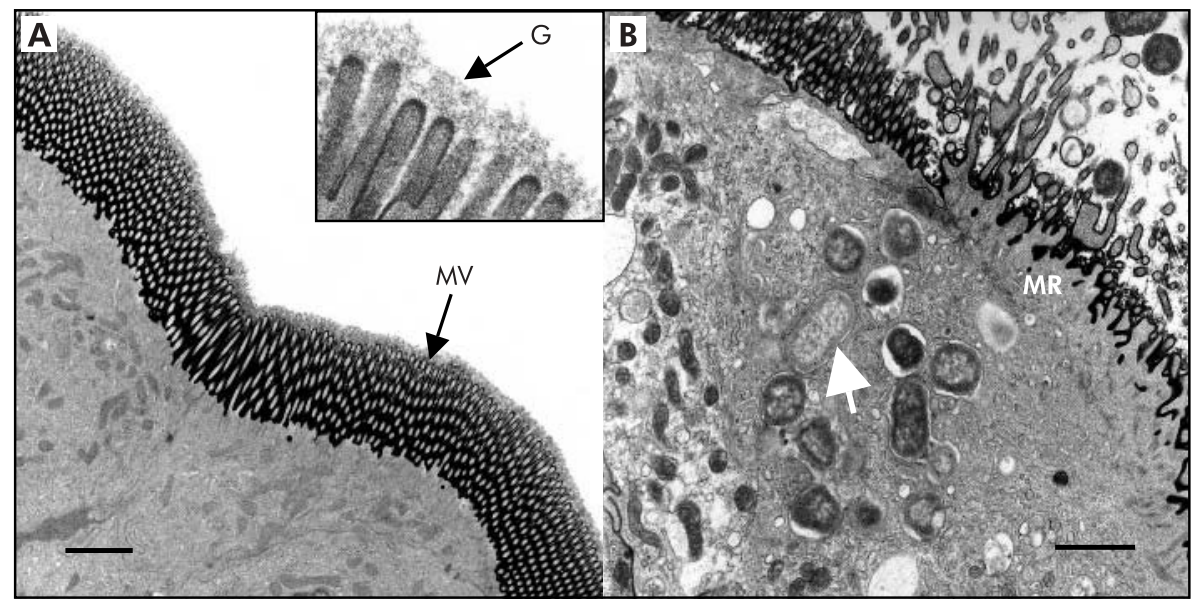

Figure 5 Salmonella enterica serovar typhimurium (S typhimurium) TML invades human terminal ileal epithelial tissue. Transmission electron microscopy (TEM) analysis of human terminal ileal epithelial tissue incubated by in vitro organ culture (IVOC) for eight hours without addition of any bacteria (A) revealed epithelial cells exhibiting at their apical surface both ordered microvilli $(M V)$ and a glycocalyx layer $(G)(A$, inset image) covering the tips of the microvilli. TEM analysis of human terminal ileal epithelial tissue incubated by IVOC for eight hours with $S$ typhimurium TML (bar $=1 \mu \mathrm{m}$ ) (B) revealed the presence of intracellular bacteria contained within endocytic vesicles (white arrow) adjacent to areas of microvillous damage and possible membrane ruffling (MR). Bar $=1 \mu \mathrm{m}$.

Evidence provided by light and electron microscopy studies indicated that most $S$ typhimurium TML bacteria were associated with mucus after four hours of incubation with IVOC. However, it was possible that cellular invasion could have occurred but at a much lower frequency than that observed in experiments using C2BBe cells (fig 1) or in bovine loop assays (fig 2 ). In order to assess cellular invasion, terminal ileal biopsies from four patients, on four separate days, were incubated with $S$ typhimurium TML for four hours. After this time, gentamicin protection assays were performed to determine the extent of cellular invasion. The number of gentamicin protected bacteria ranged from 481 to $4083 \mathrm{cfu} /$ $\mathrm{mg}$ of tissue, with a mean of $1353 \mathrm{cfu} / \mathrm{mg}$ (table 1). Importantly, no gentamicin resistant bacteria were detected in uninfected control samples. Inoculum per mg of tissue was approximately $1.25 \times 10^{6} \mathrm{cfu} / \mathrm{mg}$. Thus the extent of cellular invasion detected in this assay after four hours of incubation ranged from $0.04 \%$ to $0.3 \%$ of the original inoculum, which was considered to be extremely low in comparison with similar assays performed with cultured epithelial cells.

In order to visualise bacteria that had avoided gentamicin killing, possibly by acquiring an intracellular niche, inoculated and uninoculated tissue samples were incubated in IVOC for 4, 6, or 8 hours, and then processed, sectioned, and stained for analysis by light microscopy. It was noted that the condition of inoculated tissue, observed in terms of villus morphology and epithelial cell layer integrity, remained well preserved even eight hours after incubation with $S$ typhimurium TML (fig 4A). IVOC tissue sections were examined by light microscopy to locate any areas of the epithelium where bacteria appeared to be adherent or intracellular (fig 4A-D). Such foci of interaction were searched for on tissue from five patients which had been incubated with $S$ typhimurium TML for four hours on separate days. In agreement with SEM studies it was noted that in $4 / 5$ cases no obvious interaction between bacteria and the brush border was observed and the vast majority of bacteria were situated in mucus above the apical epithelial surface (fig 4B). However, in all samples incubated for either six hours ( $3 / 3$ cases) or eight hours $(3 / 3$ cases), clear foci of interaction (both bacterial adhesion and invasion) were more readily observed (fig 4C, D). At six hours post inoculation, the frequency of bacterial foci of interaction ranged from 0.14 to 0.42 foci per villus section (fig $4 \mathrm{E}$ ). At eight hours post inoculation, the frequency with which bacterial foci of interaction were observed ranged from 0.38 to 0.89 foci per villus section (fig $4 \mathrm{E}$ ). With $2 / 3$ biopsies where $S$ typhimurium TML had been incubated with human distal ileal tissue for eight hours, the number of foci of bacterial/ epithelial interactions observed on a $4 \mu \mathrm{m}$ thick slice through a villus approached a frequency of 1 . Foci of interaction, particularly sites of epithelial cell invasion and membrane ruffling, were also observed by TEM (fig 5B) where the ordered arrangement of microvilli and the glycocalyx layer normally observed at the apical surface of terminal ileal epithelial cells in uninfected tissue (fig 5A) appeared significantly disrupted.

\section{DISCUSSION}

No published studies to date have investigated the interaction of invasive Salmonella with fully differentiated human gut mucosal tissues. Thus we know very little about the early events associated with invasive human Salmonella disease and have to rely on information gleaned from studies utilising in vitro cultured epithelial cells, murine infections, or comparative studies with farm animal species. Consequently, to investigate the early events that occur during Salmonella interaction with fully differentiated human terminal ileal epithelial tissue, we utilised a previously established IVOC culture system..$^{7-10} 1920$ Initially, we verified the enteropathogenicity of $S$ typhimurium TML using two established model systems, C2BBe cells and bovine ligated ileal loops. S typhimurium TML associated strongly with C2BBe monolayers. $^{21-23} S$ typhimurium TML was also enteropathogenic in terms of inducing fluid secretory responses and eliciting significant mucosal damage in bovine ligated loops. ${ }^{24}$ Therefore, we concluded that $S$ typhimurium TML was invasive and enteropathogenic in $\mathrm{C} 2 \mathrm{BBe}$ cells and bovine ligated ileal loops, respectively.

We observed that when human terminal ileal epithelial tissue was exposed in many independent experiments to $S$ typhimurium TML rapid large scale invasion of enterocytes did not occur. Rather, the kinetics of this invasion appeared to be much slower and limited in comparison with those observed in previous in vivo studies. ${ }^{12} 2526$ Although invasion levels were low, large numbers of bacteria were present in mucus overlying human IVOC brush border membranes two hours post infection and only infrequent interaction of bacteria with epithelial cell surfaces were apparent four hours post 
infection. The mucus layer was only apparent in S typhimurium TML infected IVOC samples and is likely to be freshly synthesised in response to infection. Thus this mucus layer may be inhibiting bacterial interaction with host cells. It was not until later time points that bacteria/epithelial cell interactions were readily observed, and consistent with this, the gentamicin protection assays suggested only low levels of invasion of the tissue had occurred at four hours post infection. The reasons for the comparatively low levels of invasion in IVOC are unclear. Another potentially significant difference between IVOC compared with infection in vivo is that the IVOC system does not facilitate recruitment of cells such as neutrophils or dendritic cells. Recruitment of neutrophils and other cells of the immune system during an in vivo infection could promote local cytokine production, inflammation, and potentially tissue damage. Dendritic cells have been shown by others to provide an alternative pathway for penetration of the mucosal brush borders by Salmonella. ${ }^{27}$

It is also possible that the in vitro conditions utilised in IVOC could affect expression of genes influencing invasion, such as those encoding the Salmonella pathogenicity island-1 type III secretion system invasion apparatus. A further explanation for the low levels of invasion observed in this study could be the lack of M cells in the tissue used. It would have been interesting to study the interactions of $S$ typhimurium TML with human $M$ cells located in lymphoid follicle associated intestinal epithelium to assess the role of $\mathrm{M}$ cells in Salmonella invasion of human intestines. However, such explanted tissue was seldom available, and therefore extensive studies were not undertaken. However, preliminary studies using lymphoid follicle associated terminal ileal epithelial tissue did not suggest preferential invasion of follicle associated epithelium (data not shown).

By using the IVOC system to study the interactions of $S$ typhimurium with human gut epithelial tissue, we have provided evidence of bacteria/epithelial cell interaction, cellular invasion, and membrane ruffling. For these reasons, we believe that the IVOC system is consistent with other models of Salmonella/epithelial cell interaction. ${ }^{28-30}$ Interestingly, IVOC maintained tissue continues to produce a mucus layer during culture and this provides a novel model to monitor the impact of mucus on $S$ typhimurium interaction with enterocytes. Thus generation of muci and the appearance of membrane ruffles suggests that explanted cells are stimulated to express novel enzymes and cell pathways on exposure to $S$ typhimurium. Thus in the future, it might be possible to use the IVOC system to monitor aspects of the early host gene response to Salmonella. In support of this, we have measured levels of interleukin 8 associated with IVOC maintained tissue incubated with $S$ typhimurium TML and have found preliminary evidence for induction of interleukin 8 expression after $S$ typhimurium infection (our unpublished data). In further experiments it might be possible to utilise DNA microarrays combined with laser dissection microscopy to improve the scope of such gene expression studies.

In conclusion, we believe that the IVOC system provides an additional valuable alternative model for studying the early events of Salmonella associated gastroenteritis in the human intestine. IVOC offers the advantage that the infecting bacteria encounter populations of organised and fully differentiated human intestinal cells rather than homogeneous monolayers of cells. This model could be further exploited in the future to look at a range of different Salmonella serovars and mutant derivatives.

\section{ACKNOWLEDGEMENTS}

This work was supported by the Wellcome Trust, by a grant from the EU, and by a DEFRA fellowship award.

\section{Authors' affiliations}

A Haque, F Bowe, G Frankel, G Dougan, Centre for Molecular Microbiology and Infection, Department of Biological Sciences, Imperial College of Science, Technology, and Medicine, London, UK R J Fitzhenry, M Thomson, R Heuschkel, S Murch, A D Phillips, Centre for Paediatric Gastroenterology, Royal Free Hospital and University College Medical School, London, UK

M P Stevens, T S Wallis, Institute of Animal Health, Compton, Berkshire, UK

\section{REFERENCES}

1 Chalker RB, Blaser MJ. A review of human salmonellosis: III. Magnitude of Salmonella infection in the United States. Rev Infect Dis 1988; 10:111-24.

2 Henson S. Estimating the incidence of food-borne Salmonella and the effectiveness of alternative control measures using the Delphi method. Int $J$ Food Microbiol 1997;35:195-204.

3 Jones BD, Falkow S. Salmonellosis: host immune responses and bacterial virulence determinants. Annu Rev Immunol 1996;14:533-61.

4 Galan JE. Salmonella interactions with host cells: type III secretion at work. Annu Rev Cell Dev Biol 2001;17:53-86.

5 Everest $\mathbf{P}$, Ketley J, Hardy S, et al. Evaluation of Salmonella typhimurium mutants in a model of experimental gastroenteritis. Infect Immun 1999;67:2815-21.

6 Wallis TS, Galyov EE. Molecular basis of Salmonella-induced enteritis. Mol Microbiol 2000;36:997-1005.

7 Hicks S, Frankel G, Kaper JB, et al. Role of intimin and bundle-forming pili in enteropathogenic Escherichia coli adhesion to pediatric intestinal tissue in vitro. Infect Immun 1998;66:1570-8.

8 Phillips AD, Navabpour S, Hicks S, et al. Enterohaemorrhagic Escherichia coli 0157:H7 target Peyer's patches in humans and cause attaching/effacing lesions in both human and bovine intestine. Gut 2000;47:377-81.

9 Reece S, Simmons CP, Fitzhenry RJ, et al. Site-directed mutagenesis of intimin alpha modulates intimin-mediated tissue tropism and host specificity. Mol Microbiol 2001;40:86-98.

10 Fitzhenry RJ, Reece S, Trabulsi LR, et al. Tissue tropism of enteropathogenic Escherichia coli strains belonging to the $\mathrm{O} 55$ serogroup. Infect Immun 2002;70:4362-8.

11 Giannella RA, Formal SB, Dammin GJ, et al. Pathogenesis of salmonellosis. Studies of fluid secretion, mucosal invasion, and morphologic reaction in the rabbit ileum. J Clin Invest 1973;52:441-53.

12 Watson PR, Paulin SM, Bland AP, et al. Characterization of intestinal invasion by Salmonella typhimurium and Salmonella dublin and effect of a mutation in the invH gene. Infect Immun 1995;63:2743-54.

13 Sambrook J, Fritsch EF, Maniatis T. Molecular cloning techniques. New York: Cold Spring Harbor Laboratory Press, 1989.

14 Wallis TS, Starkey WG, Stephen J, et al. The nature and role of mucosal damage in relation to Salmonella typhimurium-induced fluid secretion in the rabbit ileum. J Med Microbiol 1986;22:39-49.

15 Hindle Z, Chatfield SN, Phillimore J, et al. Characterization of Salmonella enterica derivatives harboring defined aroC and Salmonella pathogenicity island 2 type III secretion system (ssaV) mutations by immunization of healthy volunteers. Infect Immun 2002;70:3457-67.

16 Peterson MD, Mooseker MS. Characterization of the enterocyte-like brush border cytoskeleton of the $\mathrm{C} 2 \mathrm{BBe}$ clones of the human intestinal cell line, Caco-2. J Cell Sci 1992;102:581-600.

17 Wallis TS, Paulin SM, Plested JS, et al. The Salmonella dublin virulence plasmid mediates systemic but not enteric phases of salmonellosis in cattle. Infect Immun 1995;63:2755-61.

18 Jones MA, Wood MW, Mullan PB, et al. Secreted effector proteins of Salmonella dublin act in concert to induce enteritis. Infect Immun 1998;66:5799-804

19 Browning TH, Trier JS. Organ culture of mucosal biopsies of human small intestine. J Clin Invest 1969;48:1423-32.

20 Autrup H, Barrett LA, Jackson FE, et al. Explant culture of human colon. Gastroenterology 1978;74:1248-57.

21 McCormick BA, Colgan SP, Delp-Archer C, et al. Salmonella typhimurium attachment to human intestinal epithelial monolayers: transcellular signalling to subepithelial neutrophils. J Cell Biol 1993;123:895-907.

22 Chowers Y, Cahalon L, Lahav M, et al. Somatostatin through its specific receptor inhibits spontaneous and TNF-alpha- and bacteria-induced IL-8 and IL-1 beta secretion from intestinal epithelial cells. J Immunol 2000;165:2955-61.

23 Mynott TL, Crossett B, Prathalingam SR. Proteolytic inhibition of Salmonella enterica serovar typhimurium-induced activation of the mitogen-activated protein kinases ERK and JNK in cultured human intestinal cells. Infect Immun 2002;70:86-95.

24 Watson PR, Galyov EE, Paulin SM, et al. Mutation of invH, but not stn, reduces Salmonella-induced enteritis in cattle. Infect Immun 1998;66:1432-8.

25 Takeuchi A. Electron microscope studies of experimental Salmonella infection. I. Penetration into the intestinal epithelium by Salmonella typhimurium. Am J Pathol 1967;50:109-36.

26 Francis CL, Starnbach MN, Falkow S. Morphological and cytoskeletal changes in epithelial cells occur immediately upon interaction with Salmonella typhimurium grown under low-oxygen conditions. Mol Microbiol 1992;6:3077-87 
27 Rescigno M, Rotta G, Valzasina B, et al. Dendritic cells shuttle microbes across gut epithelial monolayers. Immunobiology 2001;204:572-81.

28 Zeng H, Carlson AQ, Guo Y, et al. Flagellin is the major proinflammatory determinant of enteropathogenic Salmonella. J Immunol 2003;171:3668-74.
29 Gerwitz AT, Navas TA, Lyons S, et al. Cutting edge: bacterial flagellin activates basolaterally expressed TLR5 to induce epithelial proinflammatory gene expression. J Immunol 2001;167:1882-5.

30 Finlay BB, Falkow S. Salmonella interactions with polarized human intestinal Caco-2 epithelial cells. J Infect Dis 1990;162:1096-106.

\section{EDITOR'S QUIZ: GI SNAPSHOT}

\section{A rare cause of gastrointestinal bleeding in a patient with hyper-lgE syndrome}

\section{Clinical presentation}

A 36 year old man was referred to our hospital with signs of gastrointestinal bleeding. He presented with melaena, paleness of the skin, and general weakness, worsening over the last three weeks. Vomiting was absent. The patient has been known to suffer from hyper-IgE syndrome, a primary immunodeficiency disease causing recurrent bacterial infections. During the history of the present illness, the patient described intermittent stool irregularities with dark to black colour without fresh blood for six month as well as painful bowel movements.

Laboratory values were significant for severe anaemia (haemoglobin $5.0 \mathrm{~g} / \mathrm{dl}$ ) and mild elevation of parameters reflecting inflammation (white blood cell count $13900 / \mu \mathrm{l}$, C reactive protein $2.8 \mathrm{mg} / \mathrm{dl}$ ).

The patient underwent gastroscopic examination showing flat healing defects of 4-12 $\mathrm{mm}$ in the whole circumference of the descending duodenum as well as thickened folds in this area. The lesions did not present with any signs of bleeding. Therefore, colonoscopy was performed the following day.

\section{Question}

What conclusions would you draw from these colonoscopy findings (fig 1)?

See page 1436 for answer

This case is submitted by:

M Götzberger, A Schlesinger, M Daver, W Heldwein Medizinische Klinik-Innenstadt, Klinikum der Universität München, München, Germany

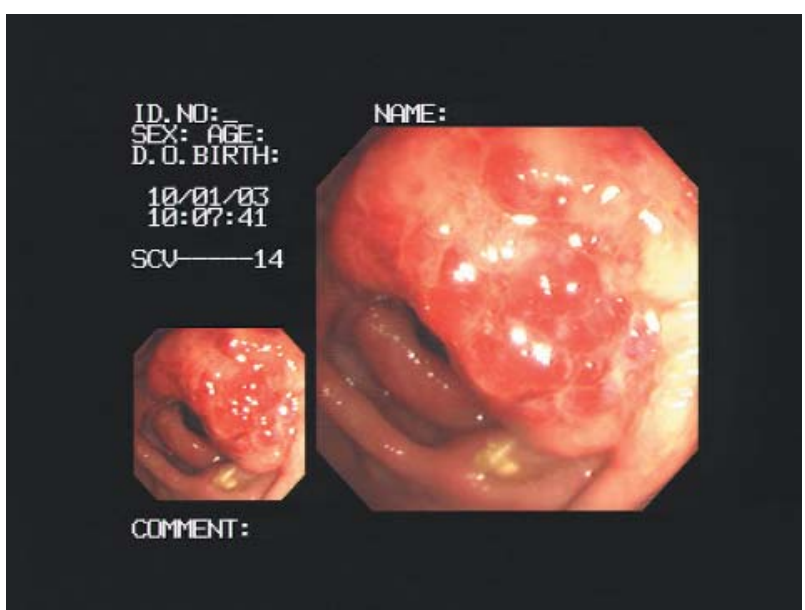

Figure 1 Endoscopic view of the colon.

A Jansson, E Renner, B H Belohradsky Haunersche Kinderklinik, Klinikum der Universität München, München, Germany

Correspondence to: $\operatorname{Dr} M$ Götzberger, Klinikum der Universität München, Medizinische Klinik-Innenstadt, Ziemssenstr 1, D-80336 München, Germany; manuela.goetzberger@med.uni-muenchen.de doi: $10.1136 /$ gut.2003.032011 